Arch Intern Med 1989; 149: 2549-2555.

7. Ginsberg JS. Management of venous thromboembolism. N Engl J Med 1996: 335(24):1816-1828.

8. Hull RD, Raskob GE, Ginsberg JS et al. A noninvaive strategy for the treatment of patient with suspected pulmonary embolism. Arch Intern Med 1994; 154: 289-297.

9. Hull RD, Nirh J, Carter CJ, et al. Pulmonary angiography ventilation lung Scanning and venography for clinically suspected pulmonary embolism with abnormal perfuion lung Scan. Ann Intern Med 1983; 98 891-9.

10. Stehling MK, Rosen MP, Weintraub J, Km D, Raptopoulos V. Spiral CT venography of the lower extremity. AJR 1994; 163: 451-453.

\section{Síndrome de Sjögren primario asociado a hepatitis autoinmune}

\section{Sr. Director:}

El síndrome de Sjögren (SS) es una enfermedad autoinmune de etiología desconocida, caracterizada por la infiltración linfocitaria de las glándulas lagrimales y salivares, provocando queratoconjuntivitis seca y xerostomía. Sin embargo, puede existir además afectación de otros órganos y aparatos. En el tubo digestivo se puede afectar no sólo la boca, sino también las glándulas exocrinas del esófago, estómago, intestino delgado y grueso (1). En el tracto hepatobiliar el SS puede asociarse con frecuencia a cirrosis biliar primaria y más raramente a colangitis esclerosante (1). Presentamos un caso de síndrome de Sjögren asociado a hepatitis crónica autoinmune, fenómeno conocido aunque poco frecuente.

Mujer de 34 años sin antecedentes de interés que consultó por sequedad de boca y sensación de cuerpo extraño en ambos ojos de 3 meses de evolución. La paciente no refería fotosensibilidad, eritema, fenómeno de Raynaud, úlceras orales o genitales, artritis, artralgias, fiebre, sudoración o pérdida de peso. La exploración física era normal. En el hemograma existía una leucocitosis mantenida con linfocitosis 13.590 leucocitos $/ \mathrm{mm}^{3}, 17 \%$ neutrófilos, $76 \%$ linfocitos, 4 monocitos, $2 \%$ eosinófilos, $1 \%$ basófilos, siendo la serie roja y las plaquetas normales. La velocidad de sedientación globular fue de 12 $\mathrm{mm}$ a la $1^{\mathrm{a}}$ hora. Las concentraciones plasmáticas de glucosa, urea, creatinina, sodio, potasio, colesterol total, triglicéridos, bilirrubina, TSH y $\mathrm{T}_{4}$ libre se encontraban dentro de los límites normales. Asimismo, el proteinograma y el estudio de coagulación fueron normales. La AST fue de 132 UI/l (normal: < $35 \mathrm{U} / \mathrm{l}$ ), la ALT de $138 \mathrm{U} / 1$ (normal: < $35 \mathrm{U} / \mathrm{L}$ ), la gamaglutamiltransferasa de $100 \mathrm{U} / 1$ (normal: < $52 \mathrm{U} / 1$ ) y la fosfatasa alcalina de $859 \mathrm{UI} / \mathrm{l}$ (normal < $250 \mathrm{U} / \mathrm{l}$ ). Las concentraciones

\section{TABLA I}

EVO LUCIÓN DE LAS ENZIM AS HEPÁTICAS EN PLASM A EN NUESTRA PACIENTE (VALO RES BASALES Y TRAS TRATAM IENTO CON DEFLAZACORT 30 M G/DÍA)

\begin{tabular}{lccccc}
\hline & BASAL & L $^{\text {ER }}$ M ES & $2^{\circ}$ M ES & $3^{\text {ER }}$ M ES & $5^{\circ}$ M ES \\
\hline AST (U/L) & 132 & 65 & 54 & 52 & 38 \\
ALT (U/L) & 138 & 85 & 72 & 70 & 42 \\
FA (U/L) & 859 & 511 & 367 & 307 & 208 \\
GGT (U/L) & 100 & 82 & 74 & 56 & 28 \\
\hline
\end{tabular}

ALT: Alanino aminotranserasa. AST: Aspartato aminotransferasa. FA: Fosfatasa alcalina. GGT: gamma-glutamil-transpeptidasa. plasmáticas de hierro, ferritina, ceruloplasmina y alfa-1-antitripsina fueron normales. Asimismo, la serología del virus de la hepatitis B y C, así como de lúes, rubéola, brucella, citomegalovirus y mononucleosis fueron negativas. Los anticuerpos antinucleares (ANA fueron positivos a un título de 1160, con un patrón mixto. El factor reumatoide y los autoanticuerpos anti DNA, Anti RNP, Anti Ro, Anti LA, Scl-70, anti Jo-1, antimitocondriales (AMA), anti músculo liso (SMA), anticélulas $\mathrm{P}$ y anti LKM-l fueron negativos. La radiografía posteroanterior de tórax y la ecografía abdominal no mostraron alteraciones patológicas. El test de Schirmer bilateral fue de $5 \mathrm{~mm}$ a los 5 minutos (normal > $10 \mathrm{~mm}$ ). En la biopsia de labio se observa a nivel de glándulas salivares atrofia acinar y denso infiltrado crónico linfocitario (grado III según la escala de Chisholm-Mason) (3). La punción-biopsia hepática con aguja de Tru-cut bajo control ecográfico, mostró unos canalículos biliares normales, necrosis hepatocitaria periportal, marcado infiltrado inflamatorio linfocitario con fibrosis subyacente en torno a dicho espacio y a nivel del lobulillo hepático, y tendencia a la formación de rosetas (Índice de Knodell: 12/22), todo ello compatible con hepatitis crónica activa. Iniciamos tratamiento con deflazacort a dosis de $30 \mathrm{mg}$ /día durante 2 meses y reducción progresiva en los parámetros bioquímicos hepáticos con el uso terapéutico del deflazacort en nuestra paciente. Habitualmente la respuesta a los corticosteroides ocurre a los pocos meses del inicio del tratamiento, debiéndose reducir la dosis progresivamente $(8,9)$. No existe, sin embargo, una guía establecida de cómo reducir dicha dosis. Además, la retirada del fármaco suele acompañarse de una recidiva del proceso hepático. En tales casos, la azatioprina a dosis de 50-150 mg/día sola o bien asociada a bajas dosis de corticosteroides, parece la opción más recomendable y efectiva $(8,10)$

\section{J. L. Zambrana García, F. Gallego Rojo, G. Cruz Caparrós, F. Díez García}

Servicio de Medicina Interna. Hospital de Poniente. El Ejido. Almería

1. Sheikh SH, Shaw-Stiffel TA. The gastrointestinal manifestations of Sjogren's syndrome. Am J Gastroenterol 1995; 90:9-14.

2. Wada T, Motoo Y, Ohmizo R, et al. Association of mixed connective tissue disease. Sjogren's syndrome and autoimmune hepatitis: Report of a case. Jpn J Med 1991; 30:278-280.

3. Fox RI, Robinson CA, Curd JG, Kosin F, Howell FV. Sjogren's syndrome. Proposed criteria for classification. Arthritis Rheum 1986; 29:577584

4. Bloch KJ, Buchanan WW, Wohl MJ, Bunim JJ. Sjogren's syndrome: A clinical, pathological and serological study of 62 cases. Medicine (Baltimore) 1965 ; 44:187-231.

5. Crowe JP, Christensen E, Butler J, et al. Primary biliary cirrhosis: The prealence of hypothyroidism and its relationship to thyroid autoantibodies and sicca syndrome. Gastroenterology 1980; 78:14371441.

6. Johnson PJ, McFarlane IG. Meeting report: International Autoimmune Hepatitis Group. Hepatology 1993; 18:998-1005.

7. Aiza I, Schiff ER. Autoimmune hepatitis. Curr Opin Gastroenterol $1995 ; 11: 238-244$

8. Krawitt EL. Autoimmune hepatitis. N Engl J Med 1996; 14:897903.

9. Sánchez-Urdazpal LS, Czaja AJ, van Hoek B, grom RAF, Wiesner RH. Prognostic features and role of livér transplantation in severe corticosteroid-treated autoimmune chronic active hepatitis. Hepatology 1992; 15:215-221.

10. Johnson PJ, McFarlane IG, Williams R. Azathioprine for long-term maintenance of remission in autoimmune hepatitis. N Engl J Med 1995; 333:958-963. 